Araştırma Makalesi / Research Paper

\title{
Üç Kızılçam Populasyonu Fidanlarının Morfolojik Özellikleri
}

\author{
Halil Barış ÖZEL ${ }^{1}$, Cengiz YÜCEDAĞ ${ }^{2 *}$, Volkan AYDINHAN ${ }^{3}$ \\ ${ }^{1}$ Bartın Üniversitesi, Orman Fakültesi, Bartın \\ 2 Mehmet Akif Ersoy Üniversitesi, Mühendislik Mimarlık Fakültesi, Burdur \\ ${ }^{3}$ Denizli Orman Fidanlığı Müdürlüğü, Denizli \\ Geliş Tarihi (Received): 14.12.2017, Kabul Tarihi (Accepted): 16.01.2018 \\ $\square$ Sorumlu Yazar (Corresponding author*): yucedagc@gmail.com \\ (C) $+902482132785 \quad$ 国 +902482132704
}

ÖZ

Çalışmada, Yılanlı-Boyalı, Acıpayam-Kelekçi ve Çameli-Göldağ kızılçam populasyonlarının fidan özellikleri bakımından gösterdikleri varyasyonlar araştııılmıştır. Ayrıca, fidan boyları ve kök boğazı çapları TS 2265/Şubat 1988'e dayanarak fidan kalite değerlendirmesi yapılmıştır. Fidan boyu ve en uzun kök boyu Acıpayam-Kelekçi populasyonunda, kök boğazı çapı ve kök sayısı Çameli-Göldağ populasyonunda ve yaprak uzunluğu ise Yılanlı-Boyalı populasyonunda en yüksek ortalama değerler olarak bulunmuştur. TSE Şubat 1988 standartlarına göre; fidanların boy bakımından $\% 60$ 'ının, çap bakımından ise \%97'sinin dikime elverişsiz fidan konumunda olduğu saptanmıştır. Sonuç olarak, üç kızılçam populasyonunun fidanları TSE fidan boyu ve kök boğazı çapı standartlarına ulaşamamıştır.

Anahtar Kelimeler: Fidan boyu, Kök boğazı çapı, Pinus brutia, Varyasyon

\section{Morphological Characters in Seedlings of Three Brutian Pine Populations}

\begin{abstract}
In the study, the variations in the characters of seedlings from Yılanlı-Boyalı, Acıpayam-Kelekçi and Çameli-Göldağ populations of Brutian pine were investigated. In addition, seedling quality evaluation was carried out in terms of the shoot height and root collar diameter according to TS 2265/February 1988. Acıpayam-kelekçi population had the highest shoot height and the longest root length, Çameli-Göldağ population had the highest root collar diameter and the number of root, and Yılanlı-Boyalı population had the highest leaf length. According to standards of TSI February $1988 ; 60 \%$ of the seedlings were found to be within the standards in terms of shoot height whereas $97 \%$ of those were unsuitable seedlings based on the root collar diameter. As a result, the seedlings of the studied populations did not achieve the root collar diameter and shoot height of TSE seedling standards given for Brutian pine.
\end{abstract}

Keywords: Shoot height, Root collar diameter, Pinus brutia, Variation

\section{Giriş}

Kızılçam (Pinus brutia Ten.) sahil ağacı ve kuraklığa dayanıklı doğal orman ağacı türlerimizden biridir. Uygun koşullarda hızlı büyüyen düzgün gövdeli bir ağaç olan kızılçam dar tepe tacı yapmakta ve ortalama $35 \mathrm{~m}$ boya ulaşabilmektedir. Tür sürekli kuvvetli rüzgârlara karşı hassastır (Gezer ve Aslan, 1980). Rakım olarak deniz seviyesinden $1650 \mathrm{~m}$ yükseltiye kadar bulunan kızılçam, Türkiye, İtalya, Yunanistan, Kıbrıs, Suriye, Lübnan, Ürdün, Filistin ve birçok Ege Denizi ve Akdeniz adalarında yayılış göstermektedir. Tür aynı zamanda 
Kuzey Irak ve Karadeniz'in kuzey kıyılarında görülmektedir (Kayacık, 1980).

Türkiye'de en geniş doğal yayılış alanına (5.610.215 ha) sahip olan kızılçam ormanlarının genel orman alanına oranı yaklaşık \%25,11'dir (Anonim, 2015). Ülkemizin önemli asli ağaç türlerinden birisi olan kızılçamın oluşturduğu ormanlar yüzyıllardan beri kuşkusuz insanoğluna sosyal ve kollektif-kültürel yararlar sağlamakla beraber, odununun bünyesi değiştirilerek ve değiştirilmeden odun kökenli sanayinin birçok alanında kullanılmaktadır. Ancak, yüzyıllardan beri türün oluşturduğu saf ve karışık ormanlara yönelik planlı ve plansız aşııı müdahaleler sonucunda bu ormanların irili ufaklı birçok kesiminden, söz konusu yararlar en az düzeyde sağlanabilmektedir (Yücedağ, 2005).

Küresel ısınmanın yaşandığı ve buna paralel olarak kuraklığa dayanıklı türlerin bir adım öne çıktığı Akdeniz iklim kuşağında hızlı gelişen bir tür olan kızılçam, büyük ölçekli ağaçlandırma programlarında yaygın olarak kullanılmaktadır. Envanter çalışmalarına göre, kızılçam ağaçlandırılması veya gençleştirilmesi gereken orman alanı yaklaşık 2.5 milyon ha'dır. Bu ağaçlandırma çaış̧maları için kızılçam fidanı üreten orman fidanlıklarında, tek ölçütlü genel bir kalite sınıflandırması uygulamak yerine, ülke çapında yapılacak ağaçlandırma çaışmalarına, gerek orijin, gerekse yöresel koşullar bakımından farklılıkları gözetecek biçimde veri üretilmesi gerekmektedir (Coşgun ve ark., 2008). Bu konuda; Demircioğulu ve ark. (2004) Türkiye için oluşturulan tek bir TSE standardının, farklı yetişme ortamı özelliklerine sahip fidanlıklar ve değişik kullanım amaçlarına cevap vermeyeceğini belirtmektedirler. Avanoğlu ve ark. (2005) ise TSE standartlarının; tür, yaş, maksimum yaş, minimum boy, kök boğazı çapı ve katıılık kriterleri yanında Avrupa standartları, fidan kullanım amacı (üretim, park-bahçe düzenlemesi, sorunlu sahalar vb.), fidan dikileceği yöre, fidan çeşidi, yetiştirme tekniği de dikkate alınarak yeniden düzenlenmesi gerekmektedir. Ağaçlandırma çalışmalarının hem ekonomik (fidan masrafı gibi) hem de biyolojik başarısı (yaşama yüzdesi, adaptasyon yeteneği gibi) için fidan özellikleri, tohum kaynağı ve bunların varyasyonu önemli bir rol oynamaktadır (Yücedağ ve ark., 2010). Bu görüşlerden hareketle bu çalışmada üç kızılçam populasyonunun fidan özellikleri bakımından gösterdikleri varyasyonlar araştırılmıştır.

\section{MATERYAL VE YÖNTEM}

2017 yılında denizden yükseltisi ortalama $450 \mathrm{~m}$ olan Denizli Orman Fidanlığı'nda yürütülen çalışmada, Yılanlı-Boyalı, Acıpayam-Kelekçi ve Çameli-Göldağ populasyonlarının 1+0 yaşlı ve çıplak köklü kızılçam fidanları materyal olarak kullanılmıştır. Fidanlarda sulama işlemi tohum çimlenmeden önce günün sıcak saatlerinde yapılmıştır. Tohum çimlendikten sonra, her gün sadece gece saatlerinde sulama işlemi gerçekleştirilmiştir. Fidanlığın yıllık ortalama yağış miktarı $45,9 \mathrm{~mm}$ olup, yazları gölgede $44,4^{\circ} \mathrm{C}$ 'ye varan ve kış ayları ise $-11,4$ ${ }^{\circ}$ C'ye kadar düşen sıcaklık görülür (Anonim, 2016). Fidanlara herhangi bir sıklık, kök kesimi vb. işlem uygulanmamıştır.

Fidanların söküm işlemleri sonbaharda büyüme ve gelişme dönemi tamamlandıktan sonra köklerine herhangi bir zarar vermeyecek şekilde gerçekleştirilmiştir. Fidan sökümünden sonra içinde su bulunan kovada kök ve sürgünlere zarar vermeyecek şekilde fidanlar dikkatlice yıkanmıştır. Daha sonra fidanların fidan boyu (FB-cm), fidan kök boğazı çapı (KBÇ-mm), en uzun kök uzunluğu (EUKU-cm), yaprak uzunluğu (YU-cm) ve kök sayıları (KS) tespit edilmiştir. Bu amaçla, populasyon başına 20 fidanda ölçümler yapılmıştır. Çalışmaya konu morfolojik özelliklerden; FB, EUKU ve EUYU cetvel yardımıyla $1 \mathrm{~mm}$ hassasiyette, $\mathrm{KBÇ}$ ise fidanın toprak altı ile toprak üstü kısmının birleştiği yerdeki çapı olup $0.01 \mathrm{~mm}$ hassasiyetli elektronik kumpas yardımıyla ölçülmüştür. Kök sayısının tespitinde ise $5 \mathrm{~cm}$ 'den büyük kökler dikkate alınmıştır. Halen yürürlükte bulunan TS 2265/Şubat 1988 (Anonim, 1988) kalite sınıflarına göre fidanlar değerlendirilmiştir. Bu sınıflamada kızılçam fidanları için kök boğaz çapının 3 mm'nin üzerinde olması önerilmiştir. Fidan boyu sınıflaması ise Tablo 1 'de verilmiştir.

Tablo 1. Kızılçama ait fidan boyu sınıflaması (Anonim, 1988)

\begin{tabular}{cccccc}
\hline & \multicolumn{5}{c}{ Fidan Yaşları } \\
\cline { 2 - 6 } Fidan Sınıfi & $\mathbf{1}$ & $\mathbf{2}$ & $\mathbf{3}$ & $\mathbf{4}$ & $\mathbf{5}$ \\
\hline I & 12 & 18 & 30 & 70 & - \\
II & 10 & 15 & 25 & 60 & - \\
III & 8 & 13 & 20 & 50 & - \\
\hline
\end{tabular}

Elde edilen verilere tek-yönlü varyans analizi, Duncan testi ve korelasyon analizleri uygulanmıştır. Analizler için SPSS programı (SPSS Inc., 2011) kullanılmıştır.

\section{BULGULAR VE TARTIŞMA}

Çalışılan kızılçam populasyonların ait ait fidan karakterleriortalamaları, varyans analizi ve Duncan testi sonuçları Tablo 2'de sunulmuştur. Buna göre, fidan boyu ve en uzun kök boyu Acıpayam-Kelekçi populasyonunda, KBÇ ve KS Çameli-Göldağ populasyonunda ve EUYU ise Yılanlı-Boyalı populasyonunda en yüksek ortalama değerler olarak tespit edilmiştir. En düşük FB ve EUKU değerleri ise Çameli-Göldağ populasyonunda bulunmuştur. Varyans analizi sonucuna göre; ENKU bakımından populasyonların ortalamaları arasında 0.01 anlam düzeyinde istatistiksel olarak fark bulunmuşken, 
diğer özellikler bakımından ortalamalar arasında fark yoktur $(p<0.05)$. EUKU populasyonlar arasında farklı çıkması, denemenin kurulduğu yetişme ortamının özelliklerine bağlı olabilir. Diğer özellikler bakımından farklılık olmaması da populasyonların lokasyonlarının yakın olmasıyla açıklanabilir.

Keskin (1992) 6 cm fidan aralığıyla yetiştirilen kızılçam fidanlarında ortalama kök boğazı çapını $3.33 \mathrm{~mm}$ ve ortalama kök sayısını ise 8 olarak bulmuştur. Aynı tür üzerinde gerçekleştirilen bir başka çalışmada, 1+0 yaşlı çıplak köklü ve tüplü fidanlarda ortalama kök boğazı çapı sırasıyla $2.37 \mathrm{~mm}$ ve $3.12 \mathrm{~mm}$ bulunmuştur (Dila- ver ve ark., 2015). Yücedağ (2005) Göller yöresinden örneklediği dört kızılçam tohum meşceresi orijinli $1+0$ yaşı çıplak köklü fidanların ortalama fidan boyunu 39 $\mathrm{cm}$, ortalama kök boğazı çapını $2.44 \mathrm{~mm}$ ve ortalama en uzun kök boyunu ise $26 \mathrm{~cm}$ olarak tespit etmiştir. Bu iki çalışmanın sonuçlarıyla mevcut çalışmanın sonuçlarının farklılık göstermesinin sebebi, çalışmaların yürütüldükleri fidanlıkların iklim ve toprak özelliklerinden kaynaklanabileceği söylenebilir. Diğer taraftan, Üçler ve ark. (2000), kızılçamda iyi görünümlü bireylerden sağlanacak tohumlardan fidan yetiştirilmesi durumunda, morfolojik olarak daha kaliteli fidan elde edilebileceğini vurgulamıştır.

Tablo 2. Populasyonlara göre özelliklerin ortalamaları ile varyans analizi ve Duncan testi sonuçları

\begin{tabular}{lccccc}
\hline Populasyon & $\begin{array}{c}\text { Fidan } \\
\text { Boyu }(\mathbf{c m})\end{array}$ & $\begin{array}{c}\text { Kök boğazı } \\
\text { Çapı }(\mathbf{m m})\end{array}$ & $\begin{array}{c}\text { En Uzun Kök } \\
\text { Boyu }(\mathbf{c m})\end{array}$ & $\begin{array}{c}\text { Yaprak Uzunluğu } \\
(\mathbf{c m})\end{array}$ & $\begin{array}{c}\text { Kök } \\
\text { Sayısı }\end{array}$ \\
\hline $\begin{array}{l}\text { Yılanlı-Boyalı } \\
\text { Acıpayam- }\end{array}$ & $6.6 \pm 0.5 \mathrm{a}^{*}$ & $1.5 \pm 0.0 \mathrm{a}$ & $27.1 \pm 1.1 \mathrm{a}$ & $1.9 \pm 0.1 \mathrm{a}$ & $13 \pm 0.5 \mathrm{a}$ \\
Kelekçi & $7.3 \pm 0.5 \mathrm{a}$ & $1.5 \pm 0.1 \mathrm{a}$ & $31.4 \pm 1.6 \mathrm{~b}$ & $1.7 \pm 0.1 \mathrm{a}$ & $13 \pm 0.8 \mathrm{a}$ \\
Çameli- & & & & & \\
Göldağ & $6.3 \pm 0.5 \mathrm{a}$ & $1.8 \pm 0.1 \mathrm{a}$ & $23.7 \pm 1.6 \mathrm{a}$ & $1.7 \pm 0.1 \mathrm{a}$ & $14 \pm 1.1 \mathrm{a}$ \\
Genel & $6.7 \pm 0.3$ & $1.6 \pm 0.0$ & $27.4 \pm 0.9$ & $1.8 \pm 0.1$ & $13 \pm 0.5$ \\
F oranı & 1.2 & 1.4 & 7.3 & 1.5 & 1.4 \\
P & 0.309 & 0.253 & 0.002 & 0.231 & 0.245 \\
\hline
\end{tabular}

*Her sütundaki aynı harfli ortalamalar istatistiksel olarak farklı değildir $(\mathrm{p}<0.05)$

Türk Standartları Enstitüsü'nün yürürlükte olan kalite sınıflarına (Anonim, 1988) göre fidanların populasyonlar bazında oransal dağılımı Tablo 3'te verilmiştir. Buna göre, fidanların boy bakımından \%60'ının, çap bakımından ise \%97'sinin dikime elverişsiz fidan konumunda olduğu saptanmıştır. Buna karşılık, Acıpayam-Kelekçi populasyonu fidanlarının \%55'i elverişli fidan sınıfında kalmışlardır. Diğer iki populasyon fidanları ise büyük oranda elverişsiz fidan sınıfında yer almıştır. Ayrıca, Bilir ve ark., (2010) tarafından TSE kalite sınıflamasının tür ve yaşla geniş farklılık göstermesi nedeniyle kalite sınıflarının bölgesel olarak hazırlanması, bölgesel ağaçlandırmaların biyolojik ve ekonomik başarısını olumlu yönde etkileyeceği belirtilmektedir. Fidan boyu bakımından diğer populasyonlara kıyasla Acıpayam-Kelekçi populasyonu fidanlarının fidan boylarının standarda göre daha elverişli olmalarının sebebi, bu populasyonun genetik özelliklerinin üstünlüğünden kaynaklanabilir. Bunlarla birlikte fidan morfolojisi ve kalitesi ile bunların varyasyonu üzerinde birçok fizyolojik, genetiksel ve çevresel faktörler vurgulanmıştır (Bilir, 1997; Dutkuner ve Bilir, 2011; Dilaver ve ark., 2015). Sonuç olarak, üç kızılçam populasyonunun fidanları TSE fidan boyu ve kök boğazı çapı standartlarına ulaşamamıştır.

Tablo 3. Fidanların TSE (1988) kalite sınıflarına dağılımı (\%)

\begin{tabular}{|c|c|c|c|c|c|c|}
\hline \multirow[b]{2}{*}{ Populasyon } & \multicolumn{4}{|c|}{ Fidan Boyu (cm) } & \multicolumn{2}{|c|}{ Kök Boğazı Çapı (mm) } \\
\hline & I. Sinıf & II. Sinıf & III. Sinıf & Elverişsiz & Elverişli & Elverişsiz \\
\hline Yılanlı-Boyalı & $\overline{5}$ & 5 & 25 & 65 & - & 100 \\
\hline $\begin{array}{l}\text { Acıpayam- } \\
\text { Kelekçi }\end{array}$ & 5 & 20 & 30 & 45 & - & 100 \\
\hline $\begin{array}{l}\text { Çameli- } \\
\text { Göldağ }\end{array}$ & & 10 & 20 & 70 & 10 & 90 \\
\hline Genel & 3 & 12 & 25 & 60 & 3 & 97 \\
\hline
\end{tabular}




\section{KAYNAKLAR}

Anonim (1988). İğne Yapraklı Ağaç Fidanları, TS 2265/Şubat1988. TSE yayınları, Ankara.

Anonim (2015). Türkiye Orman Varlığı. Orman ve Su İşleri Bakanlığı Orman Genel Müdürlüğü, 36 s., Ankara.

Anonim (2016). Denizli İli 2015 Yılı Çevre Durum Raporu. Çevre ve Şehircilik Bakanlığı Denizli Valiliği Çevre ve Şehircilik İl Müdürlüğü, 163 s., Denizli.

Avanoğlu, B., Ayan, S., Demircioğlu, N., Sivacioğlu, A., (2005). The Evaluation of 2+0-year old Black pine (Pinus nigra Arnold. subsp. pallasiana (Lamb.) Holmboe.) seedlings produced in Kastamonu-Taşköprü Forest Nursery according to the norms of Turkish Standards Institution, SIGMA: Journal of Engineering and Science, Yıldız Technical University, 2: 73-83.

Bilir, N., (1997). Doğu Karadeniz Bölgesi'nde Toros Sediri (Cedrus libani A.Rich.) Orijin Denemeleri Fidanlık Aşaması. Karadeniz Teknik Üniversitesi Fen Bilimleri Enstitüsü, Yüksek Lisans Tezi, 90 s., Trabzon.

Bilir, N., Kaya,C., Ulusan, M.D. (2010). Aydın Orijinli Fıstıkçamı (Pinus pinea L.) Fidanlarında Morfolojik Özellikler ve Fidan Kalitesi. Kastamonu Universitesi Orman Fak. Dergisi, 10: 37-43.

Coşgun, S., Şahin, M., Özkurt, N., Parlak, S. (2008). Kızılçam (Pinus brutia Ten.) Fidanlarında Kalite Sınıflarının Belirlenmesi. Batı Akdeniz Ormancılık Araştırma Enstitüsü Teknik Bülten No: 29, Antalya.

Dilaver, M., Seyedi, N., Bilir, N. (2015). Seedling Quality and Morphology in Seed Sources and Seedling Type of Brutian Pine (Pinus brutia Ten.). World Journal of Agricultural Research, 3: 83-85.

Demircioğlu, N., Ayan, S., Avanoğlu, B., Sivacioğlu, A. (2004). The Evaluation of 2+0-year old Scotch pine (Pinus sylvestris L.) seedlings produced in Kastamonu-Taşköprü Forest Nursery according to the norms of Turkish Standards Institution, Journal of Engineering, Faculty of Engineering, Pamukkale University, 2 (10): 243-251.
Dutkuner, İ., Bilir, N., (2011). Clonal repeatability for some seedling characters in Stone pine (Pinus pinea L.), Fresenius Environmental Bulletin, 20: 484-488.

Gezer, A. (1986). The sylviculture of Pinus brutia in Turkey. Le pin d'Alep et le pin brutia dans la sylviculture méditerranéenne. Paris: CIHEAM, 1: 55-66.

Gezer, A., Aslan, S. (1980). Güneydoğu Anadolu Bölgesinde İyi Gelişim Gösteren Bazı İğne Yapraklı Ağaç Türlerinin Seçimi Üzerine Araştırmalar. Ormancılık Araştırma Enstitüsü Yayınları Teknik Bülten Serisi No: 103, Ankara.

Gezer, A., Yücedağ, C. (2013). Orman Ağaçları Tohumları ve Tohumdan Fidan Yetiştirme Tekniği, Süleyman Demirel Üniversitesi Yayınları No 57, 2. Baskı, 156 s., Isparta.

Kayacık, H. (1980). Orman ve Park Ağaçlarının Özel Sistematiği 1, Gymnospermae. İstanbul Üniversitesi Orman Fakültesi Yayınları No. 26421/281, 388 s., İstanbul.

Keskin, S. (1992). Kızılçamda (Pinus brutia Ten.) Fidan Sıklığının Önemli Morfolojik Özellikler Üzerine Etkileri, Ormancılık Araştırma Enstitüsü Yayınları Teknik Bülten No: 227, Ankara.

SPSS Inc. (2011). SPSS 20.0 guide to data analysis. Prentice Hall Public. New Jersey.

Üçler, A.Ö., Gülcü, S., Bilir, N. (2000). Anadolu Karaçamı (Pinus nigra Arnold. subsp. pallasiana (Lamb.) Holmboe.) ve Kızılçamda (Pinus brutia Ten.) Tohum KaynağıMorfolojik Fidan Kalitesi İlişkileri. II. Ulusal Fidancılık Sempozyumu Bildiri Özetleri, 25-29 Eylül 2000, s. 39-45, İzmir.

Yücedağ, C. (2005). Göller Bölgesi'nde Tescilli Bazı Kızılçam Tohum Meşcerelerinin Fidecik ve 1+0 Yaşlı Fidanların Morfo-Genetik Özellikleri Üzerine Araştırmalar. Süleyman Demirel Üniversitesi, Fen Bilimleri Enstitüsü, Yüksek Lisans Tezi, 79 s., Isparta.

Yücedağ, C., Gezer A., Orhan H. (2010). The genetic variation in Crimean juniper populations from the Lakes District of Turkey. Romanian Biotechnological Letters 15: 54875492. 